\title{
Further Data on the Common Origin of Various Stem-Lines in Human Tumors
}

\author{
Corneliu D. Olinici \\ Institute of Oncology, Cluj, Romania
}

Received September 10, 1971

The stem-line concept in malignant neoplasms, first documented in rats and mice (Makino 1952, Makino 1956, Levan 1956) is supported both by experimental and clinical data (Makino et al. 1964). Although microspectrophotometrical investigations suggest that when a tumor exhibits several stem-lines, these are closely related, the filiation between the different lines of a tumor can be exactly established only by chromosomal studies; unfortunately, exact karyotyping of polyploid cells is not always possible for technical difficulties. In this paper, a human tumor with several stem-lines the relationship of which could be established by chromosome study is presented.

\section{Materials and methods}

The patient, aged 52 was addmitted for a left ovary carcinoma with ascites and metastatic right pleurisy.

Chromosomes were studied by the direct technique of Slot (1967), slightly modified. Briefly, the ascitic fluid was centrifuged and the supernatant was removed. The cells were hypotonized for $30 \mathrm{~min}$ in potassium chloride $0.075 \mathrm{M}$ at $37^{\circ} \mathrm{C}$. After 5 fixations in a cold mixture of methanol: glacial acetic acid $3: 1$, slides were made and stained with Giemsa dye.

\section{Results}

Seventy-nine metaphases were exactly counted. The results are shown in Table 1.

The majority of the cells are hypodiploid. The modal chromosome number was $38: 27$ cells ( 37.2 per cent) had 37 or 38 chromosomes (s). A minor range between 66 and 75 chromosomes was found, with 10 cells (12.6 per cent) having 74 or 75 chromosomes ( $2 \mathrm{~s})$. One cell had 138 chromosomes $(4 \mathrm{~s})$.

Karyotype analysis revealed four marker chromosomes in the hypodiploid cells: 2 large submetacentric chromosomes $\left(\mathrm{M}_{1}\right.$ and $\left.\mathrm{M}_{2}\right)$ the second being somewhat longer than the first; a long acrocentric chromosome $\left(\mathbf{M}_{3}\right)$ and a ring chromosome $\left(\mathrm{M}_{4}\right)$ (Fig. 1). The majority of the cells exhibit all these marker chromosomes, but some cells were noted with only 3 marker chromosomes; the latter cells did not show the tendency for the preferential loss of a certain marker chromosome. 
In the cells in the range of chromosome counts between 66 and 75, at least 3 out of the 4 marker chromosomes appeared in duplicate. Fig. 2 shows the karyotype of metaphase with 66 chromosomes; two $\mathbf{M}_{1}$-type chromosomes, two $\mathbf{M}_{2}$-type chromosomes, two $\mathrm{M}_{3}$-type chromosomes and one ring chromosome can be seen.

The cell with 138 chro-
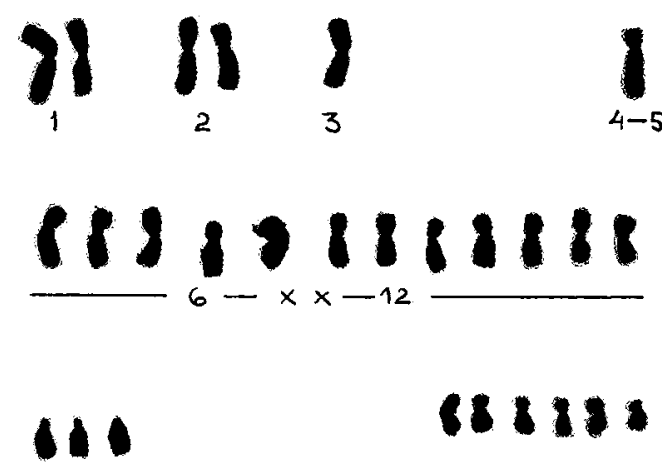

$13-15$

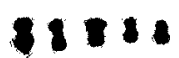

$-19-20-$

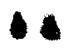

$21-22$

Fig. 1. Karyotype of a cell with 38 chromosomes. There are four marker chromosomes $\left(\mathbf{M}_{1}, \mathbf{M}_{2}, \mathbf{M}_{3}\right.$, $\mathrm{M}_{4}$ ).
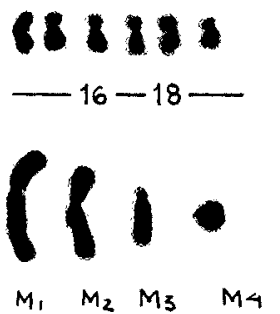

$M 4$
mosomes (Fig. 3) exhibits one submetacentric $\mathbf{M}_{1}$-type chromosome, three submetacentric $\mathbf{M}_{2}$-type chromosomes, four long acrocentrics $\left(\mathrm{M}_{3}\right.$-type) and four ring chromosomes ( $\mathbf{M}_{4}$-type). Two dicentric chromosomes (Di) and an acrocentric chromosome slightly longer than $\mathbf{M}_{3}$-type chromosomes have also been observed.

The examination of the metaphases with 46 chromosomes revealed diploid karyotypes. The metaphases with 45 chromosomes and the metaphase with 44 chromosomes were probably normal "broken" cells, judging by the chromosome morphology.

\section{IIS III

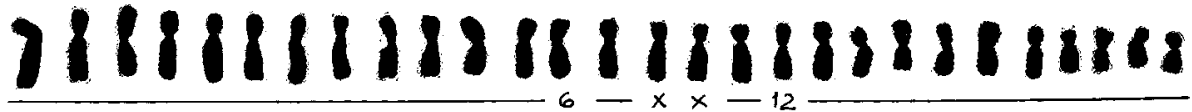
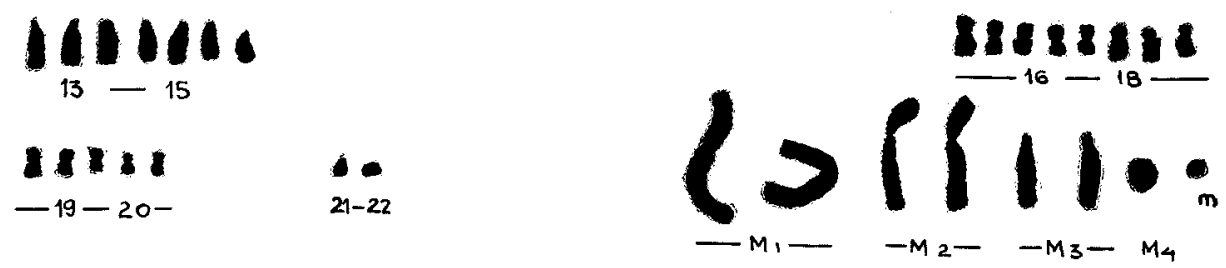

Fig. 2. Karyotype of a cell with 66 chromosomes. There are two $M_{1^{-}}$, two $M_{2^{-}}$, two $M_{3^{-}}$and one $\mathrm{M}_{4}$-type chromosomes. A minute chromosome (m) can also be seen. 


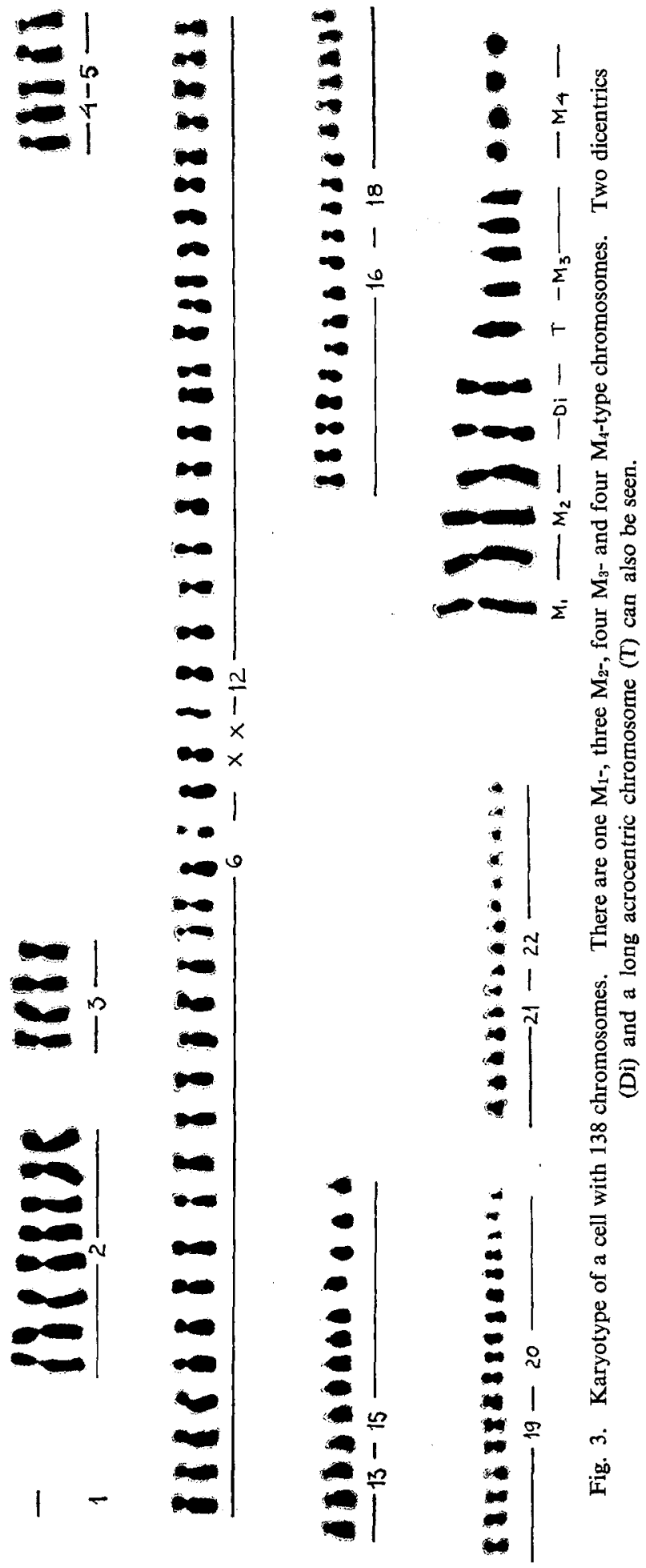




\section{Discussion}

Microspectrophotometric observations and cytogenetic studies strongly suggest the similarity of the cells belonging to the tumor stem-line (Atkin $1969 \mathrm{a}, \mathrm{b}$, Atkin et al. 1967, Hauschka 1961, Hansen-Melander et al. 1956, Ising and Levan 1959, Levan 1956, Makino 1956, Makino et al. 1959, Makino et al. 1964, Sandberg and Yamada 1966, Sandberg et al. 1967, Sandritter 1968). These observations

Table 1. Chromosome counts in 79 metaphases

\begin{tabular}{c|rrrrrrrrrr}
\hline \hline Chromosome counts & 30 & 32 & 33 & 34 & 35 & 36 & 37 & 38 & 40 & 43 \\
\hline Number of cells & 1 & 2 & 4 & 1 & 6 & 6 & 12 & 15 & 1 & 2 \\
\hline \hline Chromosome counts & 44 & 45 & 46 & 66 & 67 & 70 & 73 & 74 & 75 & 138 \\
\hline Number of cells & 1 & 3 & 10 & 1 & 1 & 1 & 1 & 4 & 6 & 1 \\
\hline
\end{tabular}

support the hypothesis that all the cells of a tumor arise from a single malignant cell (Atkin 1969 a, b, Atkin et al. 1967, Stich 1963 a, b).

The study of marker chromosomes suggests that the minor lines observed in some human tumors could have arisen from the cells belonging to the major line (Atkin 1967). In the case presented here the cells in the range of chromosome counts between 66 and 75 are clearly derived from the hypodiploid cells, by polyploidization. This fact is confirmed by the existence of a double number of marker chromosomes. Moreover, chromosome study could establish the relationship between the major line cells and the cell with 138 chromosomes. It is not clear why the doubling phenomenon does not involve in all cells, all the marker chromosomes. The probable cause, is represented by mitotic anomalies, but technical reasons ("broken metaphases") cannot be ruled out. Atkin (1970) observed that the incidence of dicentric and ring chromosomes in the tumor cells is generally low and suggested that their loss does not impair the tumor development. The constant presence of ring chromosomes in our case suggests that in some cases they "could carry genetic information necessary for the growth of the tumor"' (Katayama and Masukawa 1968).

The diploid cells are probably leukocytes or mesothelial cells which appear as a consequence of an inflammatory reaction (Ishihara and Sandberg 1963).

The data presented, strongly favor the hypothesis of the single cell origin of human neoplasms. Recent studies based on the determination of glucose-6phosphate dehydrogenase types also suggest that human tumors, both benign (Linder and Gartler 1965, Murray et al. 1971, Townsend et al. 1970) and malignant (Beutler et al. 1967, Fialkow et al. 1972, Park and Jones 1968) have, with few exceptions (Beutler et al. 1967, Smith et al. 1971), a clonal origin. The special situation of some genetically determined tumors which have enzyme patterns suggesting multiple cell origins (Flalkow et al. 1971, Gartler et al. 1966) could be explained by a common predisposition of these cells to malignant change (Fialkow et al. 1972). 


\section{Summary}

Cytogenetic findings in a malignant effusion of ovarial origin are presented. Karyotype analysis revealed the existence of several cell lines. The relationship between these lines has been established by the study of the marker chromosomes; the cells belonging to the minor lines arose by polyploidization from the major line cells. These data support the concept of the single cell origin of various cell lines in human tumors.

\section{References}

Atkin, N. B. 1967. A carcinoma of the cervix uteri with hypodipoloid and hypotetraploid stemlines. Europ. J. Cancer 3: 289-291.

- 1969a. The use of microspectrophotometry. Obst. Gynec. Surv. 24: 794-804.

- 1969b. Perimodal variation of DNA values of normal and malignant cells. Acta Cytol. 13: 270-273.

- 1970. Cytogenetic studies in human tumors and premalignant lesions: the emergence of aneuploid cell lines and their relationship to the process of malignant transformation in man. In Genetic Concepts and Neoplasia, pp. 36-56, The Williams and Wilkins Company, Baltimore.

-, Baker, M. C. and Wilson, S. 1967. Stem-line karyotypes of 4 carcinomas of the cervix uteri. Am. J. Gynec. 99: 506-514.

Beutler, E., Collins, Z. and Irwin, L. E. 1967. Value of genetic variants of glucose-6-phosphate dehydrogenase in tracing the origin of malignant tumors. New Engl. J. Med. 276: 389_ 391.

Fialkow, P. J., Martin, G. M., Klein, G., Clifford, P. and Singh, S. 1972. Evidence for a clonal origin of head and neck tumors. Int. J. Cancer 9: 133-142.

-, Sagebiel, R. W., Gartler, S. M. and Rimoin, D. L. 1971. Multiple cell origin of hereditary neurofibromas. New Engl. J. Med. 284: 298-300.

Gartler, S. M., Ziprkowki, L., Krakowski, A., Ezra, R., Szeinberg, A. and Adam, A. 1966 . Glucose6-phosphate dehydrogenase mosaicism as a tracer in the study of hereditary multiple trichoepithelioma. Am. J. Hum. Genet, 18: 282-287.

Hansen-Melander, E., Kullander, S. and Melander, Y. 1956. Chromosome analysis of a human ovarian cystocarcinoma in the ascites form. J. Nat. Cancer Inst. 16: 1067-1081.

Hauschka, T. S. 1961. The chromosomes in ontogeny and oncogeny. Cancer Res. 21: 957-974.

Ising, U. and Levan, A. 1959. The chromosomes of two highly malignant human tumors. Acta Path. Microbiol. Scand. 40: 13-24.

Ishihara, T. and Sandberg, A. A. 1963. Chromosome constitution of diploid and pseudodiploid cells in effusions of cancer patients. Cancer 16: 885-895.

Katayama, K. P. and Masukawa, T. 1968. Ring chromosomes in a breast cancer. Acta Cytol. 12: $159-161$.

Levan, A. 1956a. Chromosomes in cancer tissue. Ann. N.Y. Acad. Sci. 63: 744-789.

- 1956b. Chromosome studies on some human tumors and tissues of normal origin, grown in vivo and in vitro at the Sloan-Kettering Institute. Cancer 9: 648-663.

Linder, D. and Gartler, S. M. 1965. Glucose-6-phosphate dehydrogenase mosaicism: utilization as a cell marker in the study of leiomyomas. Science 150: 67-69.

Makino, S. 1952. A cytological study of the Yoshida sarcoma, an ascites tumor of white rats. Chromosoma 4: 649-694.

- 1956. Further evidence favoring the concept of the stem-cell in ascites tumors of rats. Ann. N.Y. Acad. Sci. 63: 818-830.

-, Ishihara, T. and Tonomura, A. 1959. Cytological studies of tumors XXVII. The chromosomes 
of thirty human tumors. Z. Krebsforsch. 63: 367-377.

-, Sasaki, M. S. and Tonomura, A. 1964. Cytological studies of tumors XL. Chromosome studies in fifty-two human tumors. J. Nat. Cancer Inst. 32: 741-777.

Murray, R. F., Jr., Hobbs, R. F. and Payne, B. 1971. Possible clonal origin of common warts (Verruca vulgaris). Nature (Lond.) 232: 51-52.

Park, I. and Jones, H. W., Jr. 1968. Glucose-6-phosphate dehydrogenase and the histogenesis of epidermoid carcinoma of the cervix. Am. J. Obst. Gynec. 102: 106-109.

Sandberg, A. A. and Yamada, K. 1966. Chromosomes and causation of human cancer and leukemia I. Karyotypic diversity in a single cancer. Cancer 19: 1869-1878.

-, Yamada, K., Kikuchi, Y. and Takagi, N. 1967. Chromosomes and causation of human cancer and leukemia III. Karyotypes of cancerous effusions. Cancer 20: 1099-1116.

Sandritter, W. 1968. DNA in carcinoma in situ and invasive cancer. Cancer Cytol. 8: 9-12.

Slot, E. 1967. A karyological study of the cancer of the ovary and the cancer cells in the ascitic effusions. Neoplasma 14: 3-10.

Smith, J. M., Townsend, D. E. and Sparkes, R. S. 1971. Genetic variants of glucose-6-phosphate dehydrogenase in the study of carcinoma on the cervix. Cancer 28: 529-532.

Stich, H.F. 1963a. Mosaic composition of preneoplastic lesions and malignant neoplasms. Exp. Cell. Res. suppl. 9: 277-285.

- 1963b. Chromosomes and carcinogenesis. In Canadian Cancer Conference, vol. 5: 99-117, Academic Press, New York and London.

Townsend, D. E., Sparkes, R. S., Baluda, M. C. and McCelland, G. 1970. Unicelluldar histogenesis of uterine leiomyomas as determined by electrophoresis by glucose-6-phosphate dehydrogenase. Am. J. Obstet. Ginec. 107: 1168-1173. 